\title{
Cách ly xã hội làm thay đổi cách tiêu dùng thế nào?
}

Hồ Mạnh Toàn

AISDL

Hà Nội, ngày 31 tháng 3 năm 2020

SSHPA EASE SciComm (31-03-2020; https://sc.sshpa.com/post/5655) - Trước tình hình cách ly xã hội diện rộng vì dịch bệnh tại nhiều nơi trên thế giới, nhu câuu tiêu dùng của người dân, đặc biệt là với các hình thức giải trí, vẫn tiếp tục gia tăng. Một số đồ dùng giải trí như máy Nintendo Switch hiện tại đã cháy hàng, kể cả các bản đã qua sử dụng. Trong khi đó, tựa game tập thể thao Ring Fit Adventure của dòng máy này cũng tăng giá phi mã từ giá gốc US\$80 lên tới trên US $\$ 100 \sim$ US $\$ 200$.

Animal Crossing is quite popular in China right now. Despite no official release, many Switch owners are importing the game from overseas to play.

Some players are creating real world scenarios in games that mirror the lockdown. E.g. Temperature checkpoint when travelling.

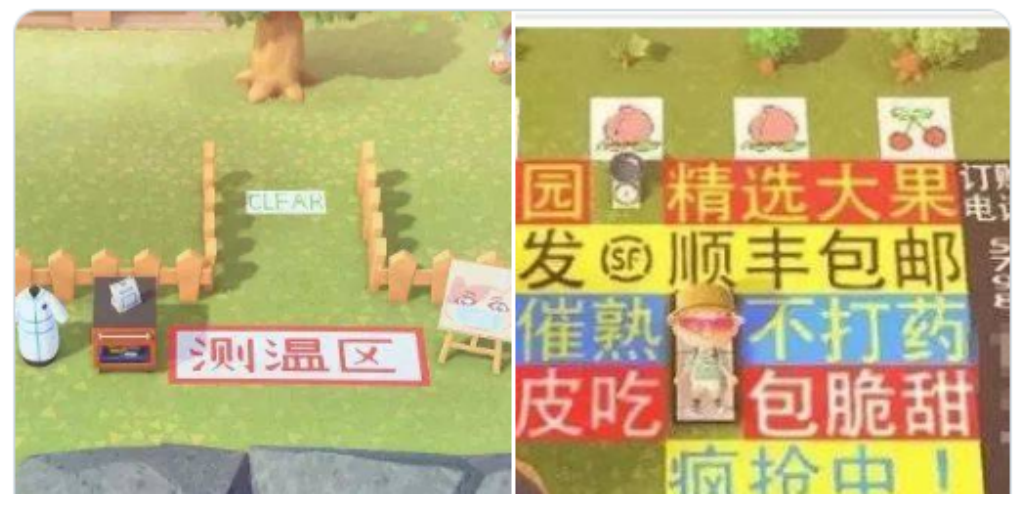

Game giả lập cuộc sông Animal Crossing: New Horizon

Mới nhất, mặc dù chưa ra mắt chính thức tại Trung Quốc nhưng tựa game giả lập cuộc sống Animal Crossing: New Horizon cũng đang gây sốt tại đây với mức giá trên US\$70. Người dùng tại Trung Quốc thậm chí còn tái hiện lại khung cảnh đời thật như tình trạng phong tỏa hay yêu câu đo nhiệt độ. 
Một dịch vụ mang lại tiện ích lớn tại gia khác là streaming phim ảnh cũng gặp tình trạng nghẽn mạng do lượng truy cập cao. Netflix đã giảm lượng băng thông xuống 25\% để tránh nghẽn mạng do nhu câu tăng mạnh tại Canada, Châu Âu, hay New Zealand.

Trong khi đó, lĩnh vực điện ảnh, truyền hình nói chung lại chứng kiến các rạp phim phải đóng cửa hàng loạt, và các bộ phim lớn cũng phải rời lịch chiếu mà chưa hẹn ngày quay lại. Tại Trung Quốc, các rạp phim chỉ vừa mới mở cửa trở lại đã bị yêu câu đóng vì nỗi lo dịch bệnh. Tại Mỹ, hơn 1200 rạp phim thuộc hệ thống $A M C$ cũng phải đóng cửa ít nhất 12 tuần kể từ ngày 17-03-2020. Hiện tại, các rạp phim tại Hà Nội và thành phố Hồ Chí Minh cũng đã đóng cửa cùng với các dịch vụ khác như quán bar, karaoke, di tích lịch sử hay danh làm thắng cảnh.

Trong tình thế khó khăn này, không chỉ người dân phải thích nghi và tìm đến môi trường ảo, ngay cả một số thương hiệu đồng hồ cao cấp, vốn không mặn mà với bán hàng online, cũng bắt đầu tiếp cận thương mại điện tử. Morgan Stanley ước tính có tới 90\% lượng tiêu thụ đồng hồ là từ bên bán lẻ thứ ba. Trong khi đó, bán hàng online chỉ chiếm đâu đó chưa đến $5 \%$. Nhưng mới đây, khách hàng đã có thể mua đồng hồ Patek Philippe qua một số nhà bán lẻ tại Anh. Sự thay đổi lớn mà COVID-19 mang đến chắc chắn sẽ còn khiến nhiều hãng đồng hồ khác phải thay đổi chiến lược kinh doanh online của mình.

Kể từ 1-4-2020, Việt Nam cũng bắt đầu cách ly toàn xã hội trong vòng 15 ngày. Một nghiên cứu chưa qua bình duyệt đăng tải ngày 23-03-2020 trên SocArXiv cũng đã nêu lên sự cần thiết của việc giảm thiểu đi lại giữa các tỉnh thành phố để tránh lây nhiễm. Nghiên cứu của tác giả Lã Việt Phương và các cộng sự đánh giá bền vững nguồn lực để chống dịch là vấn đề mà Việt Nam cần quan tâm, nhất là khi động học của dịch bệnh rất khó lường, không thể dài quyết chỉ trong trước mắt.

\section{Cường Nguyễn Việt 3 hrs -}

Hộ gia đình cầm cự được trong bao lâu?

Vậy là chính phủ đã yêu cầu 'cách ly toàn xã hội' trong 15 ngày tới. Cảc cơ sở sản xuất vẵn hoạt động nhưng phải bảo đảm khoảng cách an toàn và khử trùng theo quy định. Với những hộ gia đỉnh không có thu nhập do bị ành hưởng thì liệu tiết kiệm của họ đủ dủng trong bao lâu? Việt Nam là quốc gia có tỷ lệ tiết kiệm khá cao so với các nước xung quanh. Để tính được tỷ lệ tiết kiệm cho từng nhóm hộ, mình phải dủng dứ liệu hộ gia đình từ Khảo s... See More

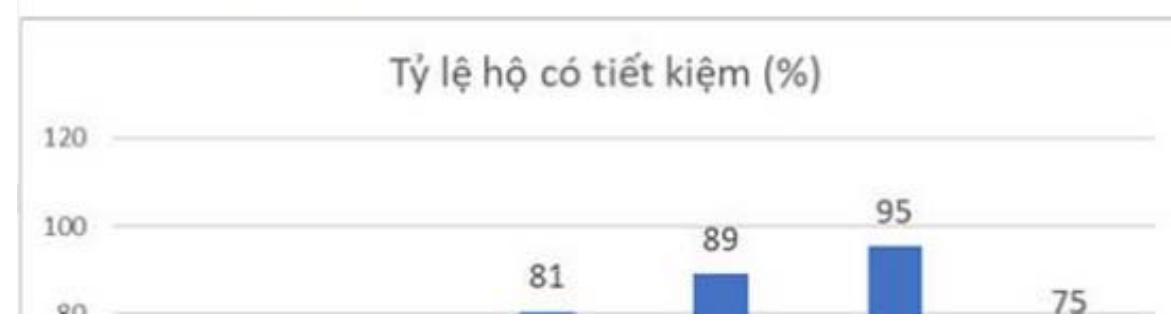

Facebook cá nhân, tác giả Nguyễn Việt Cường 
Trên Facebook cá nhân, tác giả Nguyễn Việt Cường (trường Đại học Kinh tế Quốc Dân) ước lượng nhóm 20\% hộ nghèo nhất cả nước sẽ chỉ có thể duy trì được chi tiêu trong khoảng 3 tháng nếu không có thu nhập. Vì vậy, mặc dù về cơ bản nền kinh tế vẫn hoạt động nhưng nếu cách ly kéo dài thì tác động sẽ rất nghiêm trọng.

Tuy nhiên, việc truyền thông tích cực về dịch bệnh đã phần nào giúp người dân Việt Nam tìm hiểu, và phòng bị đầy đủ cho các tình huống. Trong nghiên cứu của tác giả Huỳnh Lưu Đức Toàn (trường Đại học Kinh tế TP. Hồ Chí Minh) trên tạp chí Economics Bulletin, việc thường xuyên sử dụng mạng xã hội có các tác động tích cực tới nhận thức về dịch bệnh tại Việt Nam. Điều này cũng được nghiên cứu khác đồng thuận, khi việc tận dụng tốt các kênh truyền thông chính thống và mạng xã hội đã mang tới hiệu quả trong tuyên truyền chống dịch mà không gây hoảng loạn trong xã hội, đồng thời cũng tạo dựng niềm tin tốt với chính phủ.

\section{*Tài liệu tham khảo:}

La, V. P., Pham, T. H., Ho, T. M., Hoang, N. M., Linh, N. P. K., Vuong, T. T., ... Vuong, Q. H. (2020). Policy response, social media and science journalism for the sustainability of the public health system amid COVID-19 outbreak: The Vietnam lessons. SocArXiv Preprint. https://doi.org/10.31235/osf.io/cfw8x

Huynh, T.L.D. (2020), The COVID-19 risk perception: A survey on socioeconomics and media attention. Economics Bulletin, 40(1), 758-764. 